\title{
Application of Chromosome Microarray Analysis in the Investigation of Developmental Disabilities and Congenital Anomalies: Single Center Experience and Review of NRXN3 and NEDD4L Deletions
}

\author{
Alper Han Çebi ${ }^{a}$ Şule Altıner ${ }^{b, c}$ \\ ${ }^{a}$ Department of Medical Genetics, Karadeniz Technical University School of Medicine, Trabzon, Turkey; ${ }^{b}$ Department \\ of Medical Genetics, University of Health Sciences, Trabzon Kanuni Training and Research Hospital, Trabzon, Turkey; \\ 'Department of Medical Genetics, Ankara University School of Medicine, Ankara, Turkey
}

\section{Keywords}

Chromosomal microarray · Copy number variation ·

Developmental disabilities $\cdot N E D D 4 L \cdot N R X N 3$

\begin{abstract}
Chromosomal microarray analysis (CMA) is a first step test used for the diagnosis of patients with developmental delay, intellectual disability, autistic spectrum disorder, and multiple congenital anomalies. Its widespread usage has allowed genome-wide identification of copy number variations (CNVs). In our study, we performed a retrospective study on clinical and microarray data of 237 patients with developmental disabilities and/or multiple congenital anomalies and investigated the clinical utility of CMA. Phenotype-associated CNVs were detected in $15.18 \%$ of patients. Besides, we detected submicroscopic losses on 14q24.3q31.1 in a patient with speech delay and on 18q21.31q21.32 in twin patients with seizures. Deletions of NRXN3 and NEDD4L were responsible for the phenotypes, respectively. This study showed that CMA is a powerful diagnostic tool in this patient group and expands the genotype-phenotype correlations on developmental disabilities.

(c) 2020 S. Karger AG, Basel
\end{abstract}

\section{Introduction}

Developmental delay/intellectual disability (DD/ID) is a common condition with a prevalence of 1-3\% [Roeleveld et al., 1997]. The International Standard for the Consortium of Cytogenomic Array Consortium recommended chromosomal microarray (CMA) analysis as a first diagnostic step in patients with developmental disabilities [unexplained DD/ID or autism spectrum disorders (ASD)] or multiple congenital anomalies (MCA) [Miller et al., 2010].

CMA detects genomic gains and losses at a much higher resolution than G-banded karyotyping. Besides, it allows the identification of new copy number variations by its genome-wide design. Microarray platform, patient selection, and interpretation criteria affect the diagnostic yield of CMA, which ranges from 5-20\% according to the current literature [Sagoo et al., 2009; Miller et al., 2010].

A total of 237 patients with unexplained developmental disabilities and/or MCA were tested with CMA in this study. Genomic changes that could be associated with the phenotypes of the patients were identified in $15.18 \%$. karger@karger.com

(C) 2020 S. Karger AG, Basel

www.karger.com/msy

Karger $\stackrel{2}{=}$
Alper Han Cebi

Karadeniz Technical University School of Medicine

Department of Medical Genetics

Trabzon 601080 (Turkey)

dralphancebi@yahoo.com 
$\mathrm{DD} / \mathrm{ID}$ is an umbrella term that contains many conditions with variable severity. DD can affect motor, language, social, or intelligent skills. Besides, DD/ID can be accompanied by other neurological features or congenital anomalies. The genetic causes of DD/ID have been described as accelerating in the recent years. Despite these improvements, the interpretation of some cases could be challenging due to the rarity of genetic aberrations. We present 2 detailed reports with relatively rare CNVs in order to contribute to the literature. We detected a deletion in NRXN3 (neurexin 3) in a patient with speech delay. NRXN3 is a member of the human neurexin gene family that expresses presynaptic transmembrane proteins [Vaags et al., 2012]. Also, deletion of NEDD4L in twin patients with seizures has been accounted responsible for their phenotype. NEDD4L encodes an E3 ubiquitin ligase that regulates channel turnover and has a role in neuronal functions [Yanpallewar et al., 2016].

Briefly, the aim of this study was to investigate the diagnostic yield of CMA in a group of Turkish patients with unexplained developmental disabilities and/or MCA and to contribute to the genetic causes in DD/ID.

\section{Methods}

A total of 237 patients with unexplained developmental disabilities and/or MCA who were referred to the Department of Medical Genetics, Karadeniz Technical University School of Medicine, Trabzon, Turkey were enrolled from 2014-2019 for CMA analysis. CMA was performed as the first step test. Every patient underwent a detailed evaluation by a medical geneticist, which included prenatal and birth history, pedigree, family history, and detailed clinical and dysmorphology examinations.

Peripheral blood specimens were used for all genetic tests mentioned below. Genomic DNA was extracted using MagNA Pure Compact Nucleic Acid Isolation Kit I (Roche Diagnostic). From January 2014 to December 2017, Affymetrix, CytoScan 315K (Affymetrix CytoScan Optima $\left.{ }^{\circledR}\right)$, CytoScan $750 \mathrm{~K}$ SNP microarray platforms, and Chromosome Analysis Suite (ChAS) software were used. Each finding was analyzed with the criteria for detection by at least 20 oligonucleotide probes on the array matrix. From January 2018 to December 2019, human CytoSNP-12 Beadchip 300K array, Infinium Global Screening Array-24 V2.0 665K platforms (Illumina), and Karyostudio software was used. A copy number change was called when more than 10 consecutive probes were involved in a segment. Genomic positions were based on the UCSC February 2009 human reference sequence (hg19) (Genome Reference Consortium Human Build 37-GRCh37).

CNVs were analyzed and evaluated based on the phenotype. DECIPHER [Firth et al., 2009], Database of Genomic Variants [MacDonald et al., 2013], and Online Mendelian Inheritance in Man (OMIM) [Online Mendelian Inheritance in Man, 2020] databases were used for interpretation. CNVs were classified as benign, uncertain clinical significance, and pathogenic accord- ing to gene content and function, inheritance pattern, and documentation of multiple peer-reviewed publications [Kearney et al., 2011; Nowakowska, 2017]. Molecular karyotype results were described according to the International System for Human Cytogenomic Nomenclature [McGowan-Jordan et al., 2016] and GRCh37.

Confirmation and inheritance studies were done by karyotyping/FISH for gross aberrations, terminal aberrations, and unbalanced translocations. Unbalanced translocations were supposed in subjects with concurrent terminal copy number loss of one chromosome and terminal copy number gain of another. CNVs $<5 \mathrm{Mb}$ could not be detected with conventional karyotyping, and therefore, $5 \mathrm{Mb}$ was the line between small sized and gross aberrations. FISH and microarray studies were performed for small sized and interstitial CNVs.

\section{Results}

Our study consisted of 237 patients with MCA/mental redardation, 139 males and 98 females, between the age of 1 month and 16 years. Out of all patients studied, phenotype-associated CNVs were detected in 36 (15.18\%).

This study was done in patients with unexplained developmental disabilities and/or MCA, and CMA was performed as the first step test. We detected 44 pathogenic or likely pathogenic CNVs in 36 patients: 27 patients had one pathogenic $\mathrm{CNV}$, while 7 patients showed more than one and 2 patients, who were identical twins, had a likely pathogenic CNV with uncertain clinical significance. Table 1 provides detailed descriptions of the patients.

A defined microdeletion/microduplication syndrome in OMIM was detected in 16 of the patients (\#607872, Chromosome 1p36 Deletion Syndrome (2 patients); \#612474, Chromosome 1q21.1 Deletion Syndrome; \#194050, Williams-Beuren Syndrome; \#601362, DiGeorge Syndrome Velocardiofacial Syndrome Complex 2; \# 194072, Wilms Tumor, Aniridia, Genitourinary Anomalies and Mental Retardation Syndrome; \#130650, Beckwith-Wiedemann Syndrome; \#608636, Chromosome 15q11-q13 Duplication Syndrome; \#615656, Chromosome 15q11.2 Deletion Syndrome; \#614526, Chromosome 17q12 Duplication Syndrome; \#601808, Chromosome 18q Deletion Syndrome; \# 611867, Chromosome 22q11.2 Distal Deletion Syndrome; \# 606232, Phelan-McDermid Syndrome (2 patients); \#300979, Xq25 Duplication Syndrome; \#300815, Chromosome Xq28 Duplication Syndrome).

The size of these CNVs ranged between $108 \mathrm{~kb}$ and $79.7 \mathrm{Mb}$, and 18 of them were $<5 \mathrm{Mb}$. The majority of aberrations were losses (25 losses vs. 19 gains). 


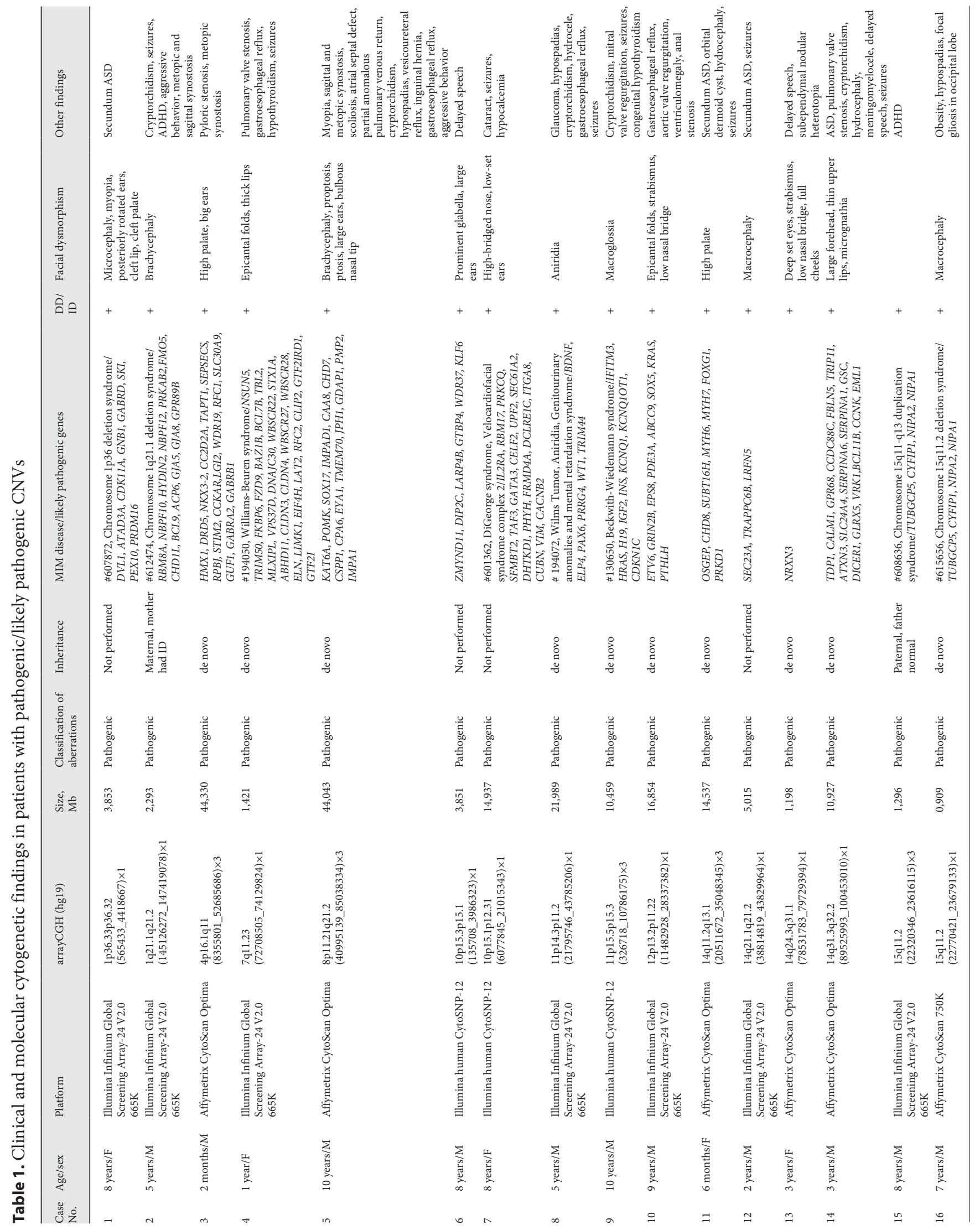




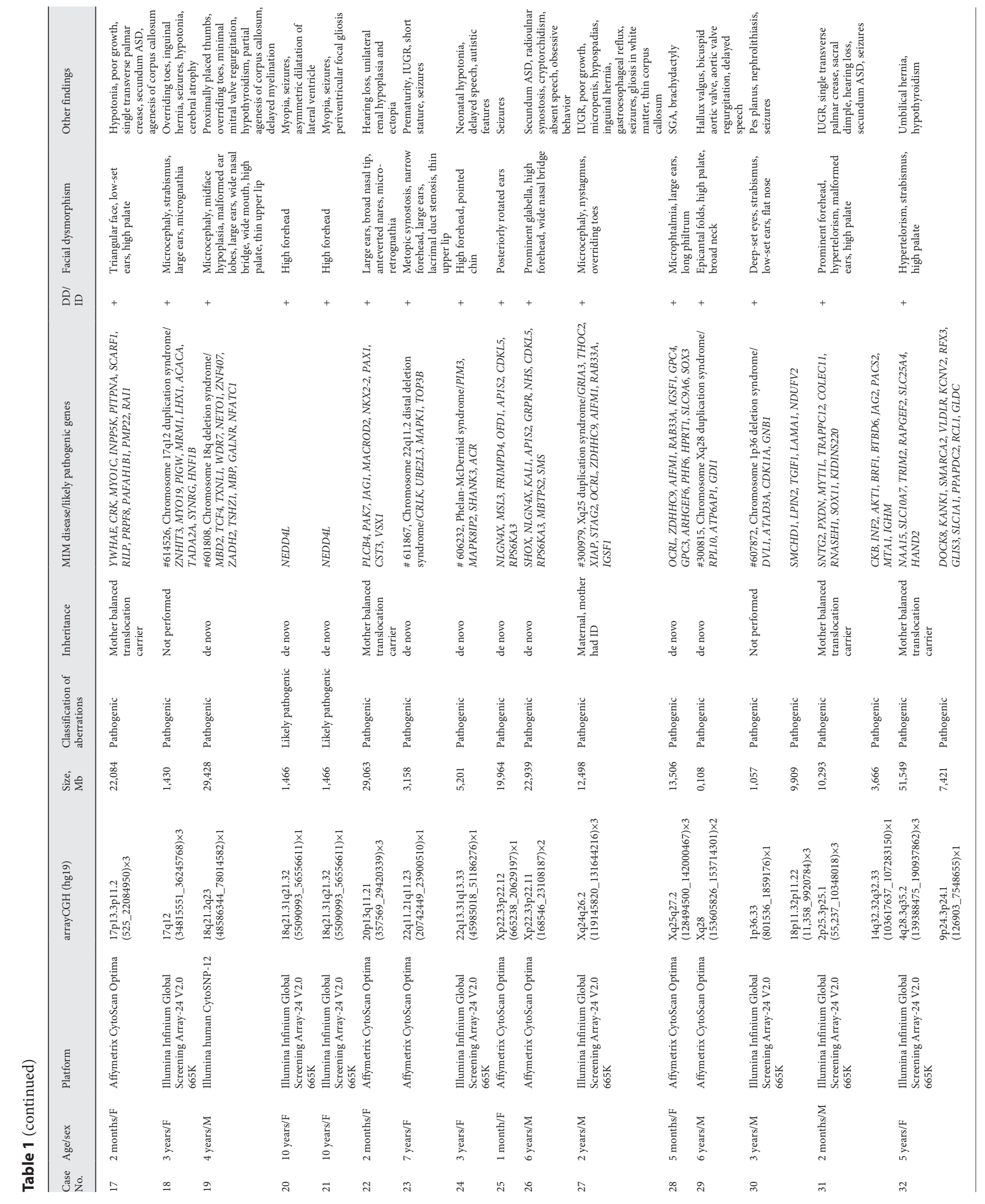




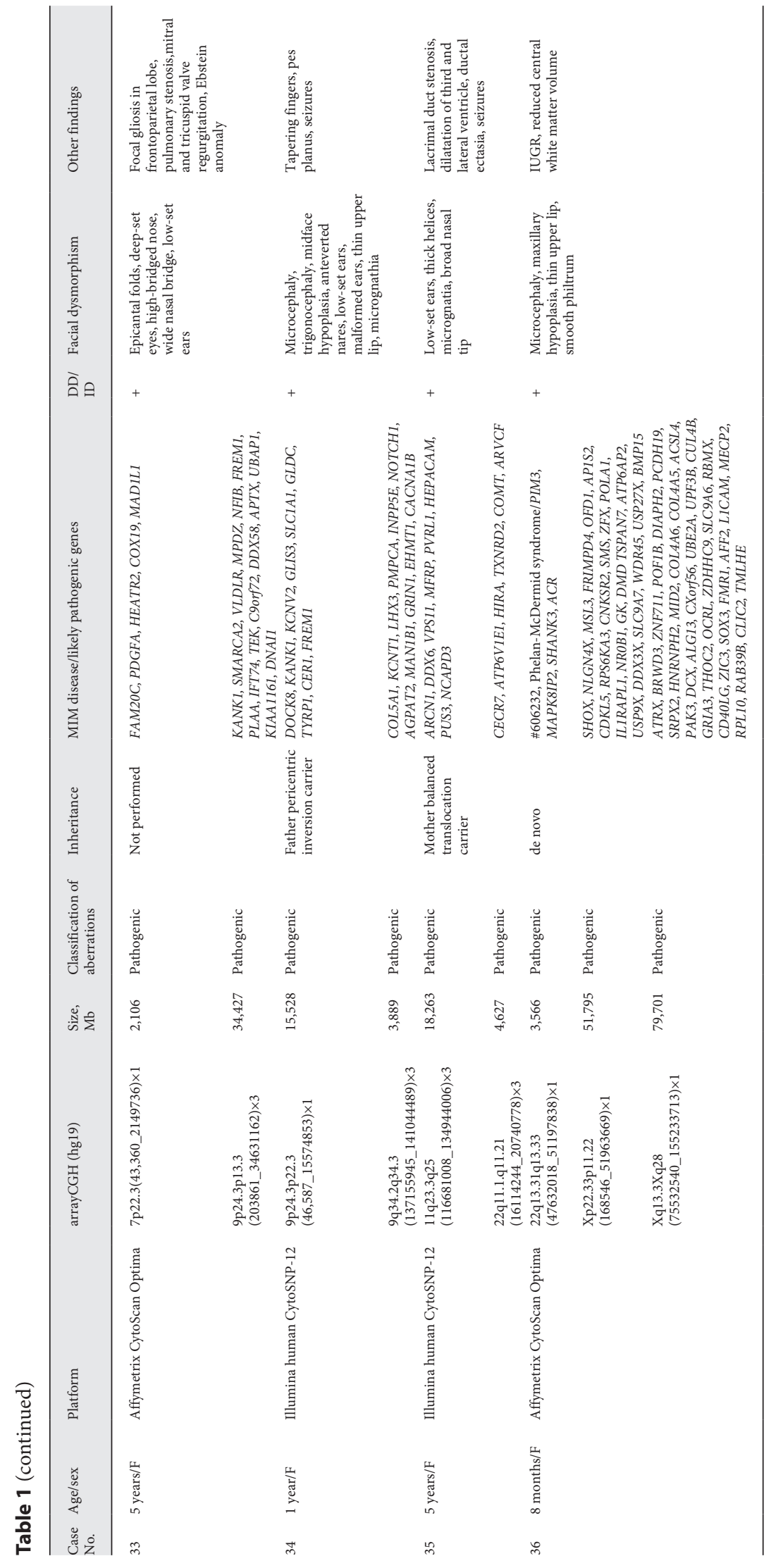




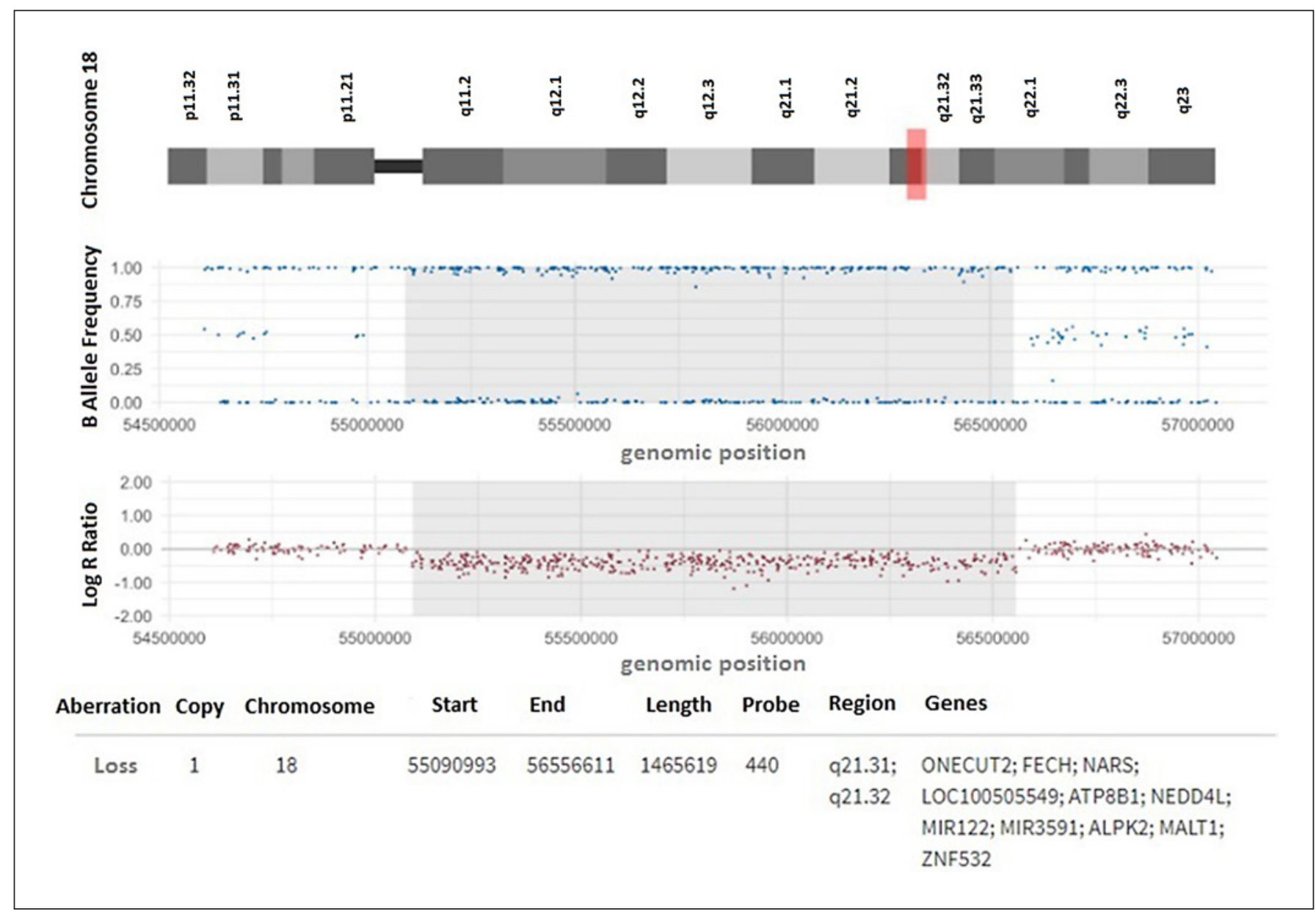

Fig. 1. Microarray analysis shows B allele frequency (middle panel) and Log R ratio (lower panel). The result represents a hemizygous copy number loss on chromosome 18q21.31q21.32 from 55090993 to 56556611 according to GRCh37/hg19. The region of loss is shown in red on chromosome 18 (upper panel). This de novo aberration was detected in both siblings (Case $\# 20$ and $\# 21$ ).

Inheritance studies were completed in $80.6 \%(29 / 36)$ of patients, and 20 had de novo CNVs. Structural chromosomal imbalance was detected in parents of 6 cases (case 17, 22, 31, 32, 34, and 35). The remaining 3 CNVs were inherited from parents with ID in 2 cases (case 2 and 27) and from phenotypically normal parents in one (case 15). In order to contribute to the literature, 2 cases are explained in detail below.

\section{Case 13}

The patient was born at term by spontaneous vaginal birth with a birth weight of $3,150 \mathrm{~g}$. She was the third child of nonconsanguineous parents and had 2 healthy siblings. The mother had no history of miscarriages or intrauterine fetal deaths. A $6 \times 8 \mathrm{~mm}$ interhemispheric cyst was detected prenatally. The family did not give consent for a prenatal genetic study.

Her measurements at 3 years of age were as follows: head circumference: $48 \mathrm{~cm}$ (25-50th percentile), height: $94 \mathrm{~cm}$ (25-50th percentile), and weight: $16 \mathrm{~kg}$ (75-90th percentile). She had dysmorphic features such as deep set eyes, strabismus, low nasal bridge, and full cheeks. She could control her head at 3 , sit unassisted at 7 , and walk at 13 months. She could say a few words at 24 months and 10 words at 36 months of age. On the other hand, she did not have stereotypical movements and developmental problems in social interaction. Subependymal nodular heterotopia was shown on a brain MRI. CMA revealed a de novo $1.198 \mathrm{Mb}$ loss at 14q24.3q31.1 (chr14:78531783_79729394) in the proband. The dele- 


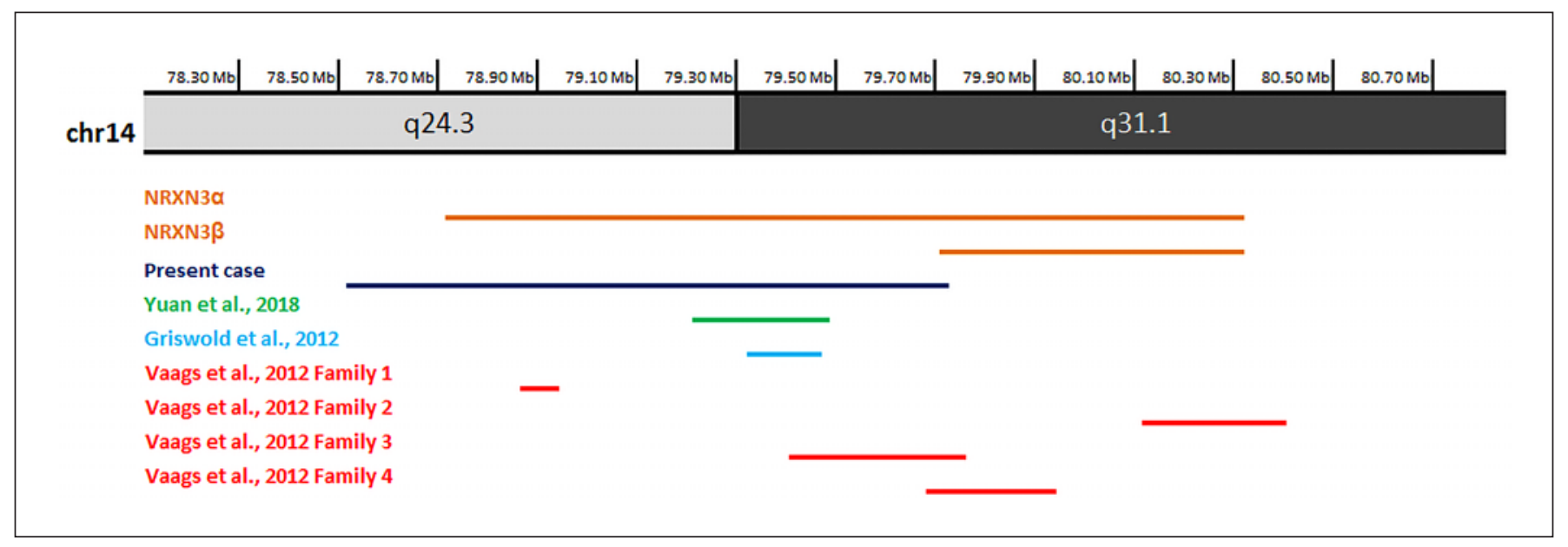

Fig. 2. Schematic view of deleted regions of cases and isoforms of NRXN3 on chromosome 14q24.3q31.1. Case\#13 is referred to as present case. Genomic coordinates are shown according to GRCh37/.

tion overlaps with the $5^{\prime}$-region of the NRXN3 gene, including coding exons.

\section{Cases 20 and 21}

The patients were 10 -year-old identical twin sisters, who suffered from rolandic epilepsy since the age of 3 years. They were born at term by caesarean section. Case 20 had a birth weight of 2,600 $\mathrm{g}$ (50th percentile) and case 21 had 2,800 g (50-75th percentile). Their parents were nonconsanguineous and had a healthy sibling. The mother had no history of miscarriages or intrauterine fetal deaths.

The girls could control theirs heads at 4 , sit at 9, and unassistedly walk at 20 months. They could say a few words at 18 months. Seizure history started at 3 years of age, and they still had attacks despite medication. Electroencephalogram revealed centrotemporal spikes. Asymmetric dilatation of the lateral ventricle was shown on a brain MRI of case 20. Likewise, periventricular focal gliosis was detected in case 21.

Her measurements at 10 years of age were as follows: head circumference: $53 \mathrm{~cm}$ (50th percentile), height: 134 $\mathrm{cm}$ (25-50th percentile), and weight: $28 \mathrm{~kg}$ (25-50th percentile). They both had a high forehead and myopia. Their intelligence was normal, and the family history was unremarkable. Microarray analysis revealed the same de novo aberration in both patients: a $1.466-\mathrm{Mb}$ loss at 18q21.31q21.32 (55090993_56556611). The deleted region spans ONECUT2, FECH, NARS, ATP8B1, NEDD4L, ALPK2, MALT1, and ZNF532 (Fig. 1).

CMA Analysis and Review of NRXN3 and NEDD4L Deletions

\section{Discussion}

ID/DD is a heterogenous group of disorders, which requires an investigational approach to determine the etiology. CMA is the first step test in this patient group [Miller et al., 2010]. Finding the underlying causes helps in disease management, provides genetic counseling, and offers prenatal diagnosis for future pregnancies [Rauch et al., 2006].

In this study, genomic changes that could be associated with the phenotypes of the patients were identified at a rate of about $15.18 \%$ with CMA, which is consistent with the current literature: the diagnostic yield of CMA is in a wide range of 5-20\% [Sagoo et al., 2009; Miller et al., 2010]. Patient number and selection criteria, interpretation criteria, and type of CMA platform used are considered effective factors in this difference [Miller et al., 2010].

A known microdeletion/microduplication syndrome was detected in 16 of the cases. It can be explained by specific syndromes that were not considered due to subtle clinical features.

A higher number of losses were responsible for the phenotype in this study (25 losses vs. 19 gains). Gains may present with milder phenotypes, which could result in a selection bias [attaglia et al., 2013].

Case 13 presented with subtle dysmorphic features and speech delay. A 1.198-Mb microdeletion at chromosome $14 \mathrm{q} 24.3 \mathrm{q} 31.1$ spaning the NRXN3 gene was responsible for the phenotype. Neurexin 1 (NRXN1), neurexin 2 (NRXN2), and neurexin 3 (NRXN3) are members of the human neurexin gene family of presynaptic 
transmembrane proteins that alter the synaptic function and intervene with nerve signal conduction. Each of the genes produces alpha and beta isoforms [Vaags et al., 2012]. Alpha neurexins were shown to affect neurotransmitter release via voltage dependent $\mathrm{Ca}^{2+}$ channels [Zhang et al., 2005; Dudanova et al., 2006]. Mutations and deletions of NRXN1, NRXN2, and NRXN3 are associated with a wide variety of neurodevelopmental conditions. Mutations of all 3 genes were identified in patients with ASD [Kasem et al., 2018]. The genomic region resembling our case was published by Yuan et al. [2018]. Exonic deletions of alpha isoform of NRXN3 were shown in a 3-generation family. Although only the proband had dysmorphic fascial findings, all individuals carrying the deletion had variable neurodevelopmental disorders. Also, CNVs of NRXN3 were shown in ASD patients [Griswold et al., 2012; Vaags et al., 2012]. The aforementioned deleted regions of the cases are shown in Figure 2. Larger genomic losses were also defined in this region. Riegel et al. [2014] presented a case with a 13.11-Mb loss on $14 \mathrm{q} 24.3 \mathrm{q} 31.3$ with dysmorphic treats, moderate developmental delay, and mild mental retardation. Cingoz et al. [2011] published another case with a 23-Mb loss on $14 \mathrm{q} 24.3 \mathrm{q} 32.2$ in a patient with $\mathrm{DD}$, language impairment, dysmorphic face, and congenital heart defect. Although an essential role of NRXN3 in the phenotypic finding of patients with 14q24.3q31.1 deletions was discussed in several reports, its relation with speech delay is validated with this case.

Cases 20 and 21 were 10 -year-old identical twin sisters diagnosed with rolandic epilepsy. They had a 1.466-Mb loss on chromosome 18q21.31q21.32. ONECUT2, FECH, NARS1, ATP8B1, NEDD4L, ALPK2, MALT1 and ZNF532 genes are located at this genomic region. ONECUT2, NARS1, ALPK2, and ZNF532 have not been associated with a disease yet. Biallelic mutations of $F E C H$ are associated with erythopoietic porphyria [Schneider-Yin et al., 2000]. Although biallelic mutations of ATP8B1 were identified in progressive familial intrahepatic cholestasis [Klomp et al., 2004], heterozygous mutations were shown to cause intrahepatic cholestasis of pregnancy [Müllenbach et al., 2005]. Homozygous MALT1 mutations were shown to result in immunodeficiency [Jabara et al., 2013].

$N E D D 4 L$ is highly expressed in the brain. It is an ubiquitin protein ligase that regulates ion channel internalization and turnover in the central nervous system. The NEDD4L protein contains an N-terminal C2 domain that binds to $\mathrm{Ca}^{2+}, 2-4 \mathrm{WW}$ protein-protein interacting domains, and a HECT ubiquitin ligase domain at the C-ter- minal end [roix et al., 2016]. Heterozygous mice models were found hyperactive, had increased basal synaptic transmission, and an enhanced sensitivity to inflammatory pain. Mutations of NEDD $4 L$ are suggested to be involved in neuropsychological deficits in humans [Yanpallewar et al., 2016]. Heterozygous mutations were reported in patients with neurodevelopmental disorders. HECT domain mutations cause periventricular nodular heterotopia 7 (MIM\#607201), which is characterized by periventricular nodular heterotopia, cleft palate and toe syndactyly, developmental delay, and seizures in some patients [roix et al., 2016; Kato et al., 2017; Elbracht et al., 2018]. On the other hand, WW domain mutations were shown to cause photosensitive generalized epilepsy [Dibbens et al., 2007].

The patients had rolantic epilepsy and several findings in a brain MRI: case 20 had an asymmetric dilatation of the lateral ventricle and case 21 had periventricular focal gliosis. Although missense mutations were reported to date, our cases are remarkable being the first with a deletion. According to the current literature, NEDD $4 L$ has a revealing gene function that is relevant to referral reason. Hence, loss on chromosome 18q21.31q21.32 (55090993_56556611) was interpreted as likely pathogenic. Heterozygous NEDD4L deletions should also be considered in patients with epilepsy.

Case 28 was also remarkable. The patient was a 5-month-old girl with microphaltmia and subtle dysmorphic features. A 13.506-Mb microduplication at chromosome Xq25q27.2, spanning the SOX3 gene, was responsible for her phenotype. Mutations of $S O X 3$ were reported as causative for microphtalmia with mental retardation. Also gains and losses containing SOX3 have been reported several times in variable phenotypes [Jelsig et al., 2018]. Gain of SOX3 probably contributed to the phenotype of the patient via favorably skewed X-inactivation.

\section{Conclusion}

This study redemonstrated that CMA is a first step diagnostic tool in patients with developmental disabilities and/or MCA. However, the underlying cause of the phenotype cannot be determined in almost $50 \%$ of the patients [Miller et al., 2010]. Therefore, new CMA platforms should be developed accordingly and new diseases causing regions are discovered. Besides, next-generation techniques are alternatives in unsolved cases. With development in technology, next-generation sequencing can also 
provide $\mathrm{CNV}$ information, but this technique is in necessity of specific bioinformatic data. For this reasons, CMA probably remains the first step in diagnostic approaches.

CMA also allows the identification of new CNVs by its genome-wide design [Miller et al., 2010]. This study provided new cases with NRXN3 and NEDD $4 L$ deletions and expands the genotype-phenotype correlations on developmental disabilities.

\section{Statement of Ethics}

This work was approved by the Institutional Ethics Committee. Informed written consent was obtained from the patient's parents or guardians.

\section{Conflict of Interest Statement}

The authors have no conflicts of interest to declare.

\section{Author Contributions}

A.H.Ç. obtained the patient information, analyzed the data, designed the work, and wrote the manuscript. Ş.A. analyzed the data and contributed to the manuscript. All authors read and confirmed the final manuscript.

\section{Data Availability}

The data that support the findings of this study are available on request from the corresponding author.

\section{References}

Battaglia A, Doccini V, Bernardini L, Novelli A, Loddo S, Capalbo A, et al. Confirmation of chromosomal microarray as a first-tier clinical diagnostic test for individuals with developmental delay, intellectual disability, autism spectrum disorders and dysmorphic features. Eur J Paediatr Neurol. 2013;17(6):589-99.

Broix L, Jagline H, Ivanova E, Schmucker S, Drouot N, Clayton-Smith J, et al. Mutations in the HECT domain of NEDD4L lead to AKT-mTOR pathway deregulation and cause periventricular nodular heterotopia. Nat Genet. 2016;48(11):1349-58

Cingöz S, Bache I, Bjerglund L, Ropers $\mathrm{H}-\mathrm{H}$, Tommerup N, Jensen $\mathrm{H}$, et al. Interstitial deletion of 14q24.3-q32.2 in a male patient with plagiocephaly, BPES features, developmental delay, and congenital heart defects. Am J Med Genet. 2011;155(1):203-6.

Dibbens LM, Ekberg J, Taylor I, Hodgson BL, Conroy SJ, Lensink IL, et al. NEDD4-2 as a potential candidate susceptibility gene for epileptic photosensitivity. Genes Brain Behav. 2007;6(8):750-5.

Dudanova I, Sedej S, Ahmad M, Masius H, Sargsyan $\mathrm{V}$, Zhang $\mathrm{W}$, et al. Important contribution of alpha-neurexins to Ca2+-triggered exocytosis of secretory granules. J Neurosci. 2006;26(41):10599-613.

Elbracht M, Kraft F, Begemann M, Holschbach P, Mull M, Kabat IM, et al. Familial NEDD4L variant in periventricular nodular heterotopia and in a fetus with hypokinesia and flexion contractures. Mol Genet Genomic Med. 2018; 6(6):1255-60.

Firth HV, Richards SM, Bevan AP, Clayton S, Corpas M, Rajan D, et al. DECIPHER: database of chromosomal imbalance and phenotype in humans using ensembl resources. Am J Hum Genet. 2009;84(4):524-33.
Griswold AJ, Ma D, Cukier HN, Nations LD, Schmidt MA, Chung RH, et al. Evaluation of copy number variations reveals novel candidate genes in autism spectrum disorder-associated pathways. Hum Mol Genet. 2012; 21(15):3513-23.

Jabara HH, Ohsumi T, Chou J, Massaad MJ, Benson $\mathrm{H}$, Megarbane A, et al. A homozygous mucosa-associated lymphoid tissue 1 (MALT1) mutation in a family with combined immunodeficiency. J Allergy Clin Immunol. 2013;132(1):151-8.

Jelsig AM, Diness BR, Kreiborg S, Main KM, Larsen VA, Hove H. A complex phenotype in a family with a pathogenic SOX 3 missense variant. Eur J Med Genet. 2018;61(3):168-72.

Kasem E, Kurihara T and Tabuchi K. Neurexins and neuropsychiatric disorders. Neurosci Res. 2018;127:53-60.

Kato K, Miya F, Hori I, Ieda D, Ohashi K, Negishi $\mathrm{Y}$, et al. A novel missense mutation in the HECT domain of NEDD4L identified in a girl with periventricular nodular heterotopia, polymicrogyria and cleft palate. J Hum Genet. 2017;62(9):861-3.

Kearney HM, Thorland EC, Brown KK, Quintero-Rivera F, South ST. American College of Medical Genetics standards and guidelines for interpretation and reporting of postnatal constitutional copy number variants. Genet Med. 2011;13(7):680, 5.

Klomp LW, Vargas JC, van Mil SW, Pawlikowska L, Strautnieks SS, van Eijk MJ, et al. Characterization of mutations in ATP8B1 associated with hereditary cholestasis. Hepatology. 2004; 40(1):27-38.

MacDonald JR, Ziman R, Yuen RK, Feuk L, Scherer SW. The Database of Genomic Variants: a curated collection of structural variation in the human genome. Nucleic Acids Res. 2013;42(Database issue):D986-92.
Miller DT, Adam MP, Aradhya S, Biesecker LG, Brothman AR, Carter NP, et al. Consensus statement: chromosomal microarray is a firsttier clinical diagnostic test for individuals with developmental disabilities or congenital anomalies. Am J Hum Genet. 2010;86(5):74964.

Müllenbach R, Bennett A, Tetlow N, Patel N, Hamilton G, et al. ATP8B1 mutations in British cases with intrahepatic cholestasis of pregnancy. Gut. 2005;54(6):829-34.]

Nowakowska B. Clinical interpretation of copy number variants in the human genome. $J$ Appl Genet. 2017;58(4):449-57.

ISCN 2016: An International System for Human Cytogenomic Nomenclature; McGowan-Jordan J, Simons A, Schmid M (eds). Cytogenet Genome Res ;149(1-2):1-140.

Online Mendelian Inheritance in Man, OMIM. McKusick区Nathans Institute for Genetic Medicine, Johns Hopkins University (Baltimore, MD), 2020.

Rauch A, Hoyer J, Guth S, Zweier C, Kraus C, Becker C, et al. Diagnostic yield of various genetic approaches in patients with unexplained developmental delay or mental retardation. Am J Med Genet A. 2006;140(19):2063-74.

Riegel M, Moreira LM, Espirito Santo LD, Toralles MB, Schinzel A. Interstitial 14q24.3 to q31.3 deletion in a 6-year-old boy with a non-specific dysmorphic phenotype. Mol Cytogenet. 2014;7(1):77.

Roeleveld N, Zielhuis GA, Gabreëls F The prevalence of mental retardation: a critical review of recent literature. Dev Med Child Neurol 1997;39(2):125-132. . 
Sagoo GS, Butterworth AS, Sanderson S, ShawSmith C, Higgins JP, Burton H. Array CGH in patients with learning disability (mental retardation) and congenital anomalies: updated systematic review and meta-analysis of 19 studies and 13,926 subjects. Genet Med. 2009; 11(3):139, 46.

Schneider-Yin X, Gouya L, Dorsey M, Rüfenacht U, Deybach JC, Ferreira GC. Mutations in the iron-sulfur cluster ligands of the human ferrochelatase lead to erythropoietic protoporphyria. Blood. 2000;96(4):1545-9.
Vaags AK, Lionel AC, Sato D, Goodenberger M, Stein QP, Curran S, et al. Rare deletions at the neurexin 3 locus in autism spectrum disorder. Am J Hum Genet. 2012;90(1):133-41.

Yanpallewar S, Wang T, Koh DC, Quarta E, Fulgenzi G, Tessarollo L. Nedd4-2 haploinsufficiency causes hyperactivity and increased sensitivity to inflammatory stimuli. Sci Rep. 2016;6: 32957.
Yuan H, Wang Q, Liu Y, Yang W, He Y, Gusella JF, et al. A rare exonic NRXN3 deletion segregating with neurodevelopmental and neuropsychiatric conditions in a three-generation Chinese family. Am J Med Genet B Neuropsychiatr Genet. 2018;177(6):589-95.

Zhang W, Rohlmann A, Sargsyan V, Aramuni G, Hammer RE, Südhof TC, et al. Extracellular domains of alpha-neurexins participate in regulating synaptic transmission by selectively affecting $\mathrm{N}$ - and $\mathrm{P} / \mathrm{Q}$-type $\mathrm{Ca} 2+$ channels. J Neurosci. 2005;25(17):4330-42. 